\title{
FIRST ALBERTA RECORD OF AN EASTERN BLUEBIRD
}

\section{RUDI BUTOT, 81 Capri Ave., N.W., Calgary, Alberta T2L 0C9}

On May 28, 1977, a bluebird was observed by Mr. and Mrs. J. Farish on their acreage one mile west of the Calgary city limits. The bird was believed to be either a Western or Eastern Bluebird. The area, on the edge of the Foothills at an elevation of 3700 feet, encompasses several residential developments consisting of small acreages with pasture and hay fields and abundant aspen groves. Numerous bluebird houses have been put up in this area through the years.

On June 1, 1977, Garry McKay visited the Farish property and tentatively identified a male Eastern Bluebird. Notes made at the time show a bluebird-sized bird, deep blue on head, back and wings; breast and throat rusty red, chin whitish, white underparts, faint eye ring, and dark legs. A visit by Gary and Rudi Butot on the evening of June 2, 1977, established the presence of two male Eastern Bluebirds on the Farish property. Both birds seem identical in plumage and coloration. Both were feeding near a freshly raked hay pile in the horse pasture. Little aggressive behaviour was seen between the two birds although on occasional mild skirmish took place when both were on the ground together. Most of the time the birds perched on the fence, usually 20 to 40 feet apart, but at times as close as 2 feet.

On both June 2 and 5, photographs were obtained by Rudi Butot, and the song of the birds, a soft short series of gurgling notes, was recorded. The photographs leave no doubt that the birds were Eastern Bluebirds. On June 5 , the birds were observed visiting a number of bluebird houses; however, never were both birds seen at the same nest box at the same time. One altercation was noted between one of the birds and a pair of Tree Swallows over one of the bird houses. Although Mountain Bluebirds were observed in the area on several occasions, no interaction between the two species was observed at any time.

No observations were made from June 6 to 10,1977, and only one bird was observed on June 9, 10, 11 and 12, the last date it was seen.

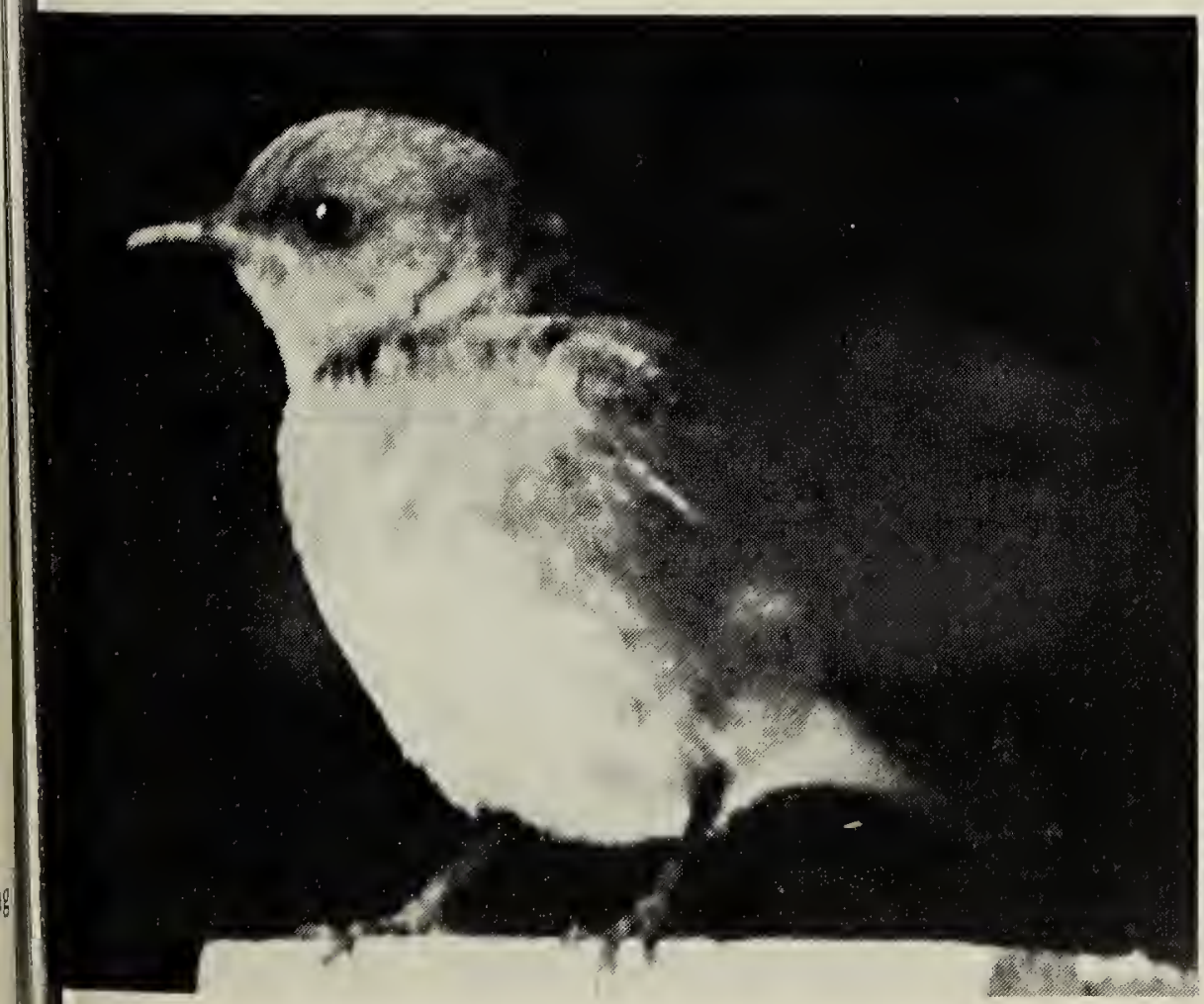

Eastern Bluebird

Rudi Butot 